\title{
O empoderamento de lideranças indígenas Kaingang no sul do Brasil
}

\author{
The empowerment of indigenous Kaingang leaders in southern Brazil
}

\section{L'autonomisation des dirigeants autochtones Kaingang dans le sud du Brésil}

\author{
El empoderamiento de los líderes indígenas Kaingang en el sur de Brasil
}

\author{
Antonio Cavalcante de Almeida \\ (antoniocavalcant@hotmail.com)
}

Recebido em 13/02/2014; revisado e aprovado em 14/07/2014; aceito em 13/11/2014

DOI: http:/ / dx.doi.org/10.1590/1518-70122015215

\begin{abstract}
Resumo: O presente artigo estudou o empoderamento de lideranças Kaingang no movimento indígena na região sul do Brasil, com ênfase no estado do Paraná. O foco da análise foram as lideranças indígenas atuantes no campo de intermediação que se inicia, sobretudo, com a participação ativa no âmbito das aldeias (Terra Indígena Mangueirinha), com as autoridades tradicionais passando pelas instituições e espaços de disputas no Estado-nação.

Palavras-chave: Empoderamento. Indígena. Liderança.

Abstract: This paper has studied the empowerment of the indigenous Kaingang leaders' movement in southern Brazil, with emphasis in the state of Paraná. The focus of the analysis was active indigenous leaders in the field of mediation that begins, especially, with their active participation in the realm of the villages (Terra Indígena Mangueirinha), with the traditional authorities moving along institutions and spaces of dispute in the nation-State. Key words: Empowerment. Indigenous people. Leadership.

Résumé: Cet article étudie l'autonomisation des leaders du mouvement autochtone Kaingang dans le sud du Brésil, en mettant l'accent sur l'État de Paraná. L'objectif de l'analyse a eté le leadership autochtone actif dans le domaine de la médiation qui commence, en particulier avec la participation active dans les villages (Terra Indígena Mangueirinha), avec les autorités traditionnelles à travers les institutions et les espaces de conflits dans l'État nation. Mots-clés: Autonomisation. Autochtones. Leadership.

Resumen: En éste trabajo se estudió el empoderamiento de los líderes de movimientos indígenas Kaingang en el sur de Brasil, con énfasis en el estado de Paraná. El análisis se enfoca en los líderes indígenas trabajando en el campo de la mediación, que comienza principalmente con la participación activa en el ámbito interno de los pueblos (Terra Indígena Mangueirinha), con las autoridades tradicionales (caciques), llegando hasta las instituciones y espacios de disputa en el Estado Nacional.

Palabras clave: Empoderamiento. Indígena. Liderazgo.
\end{abstract}

\section{Introdução}

O termo empowerment já existia antes mesmo da utilização a partir dos movimentos emancipatórios relacionados ao exercício da democracia e da cidadania, sobretudo iniciado pelo movimento dos negros, das feministas, dos homossexuais, pelo movimento dos direitos das pessoas deficientes ocorridos nos Estado Unidos e Europa na metade do século XX. Ademais, é o momento de emergência dos novos movimentos sociais exigindo mais liberdade de expressão, participação política e o cessamento do preconceito racial nas democracias políticas ocidentais. Nesse sentido, os conceitos de capital social e empoderamento ganhavam visibilidade no âmbito dos movimentos sociais e políticos no meio acadêmico.

Como se observa, o empoderamento aparece precisamente durante os anos 1970 nos estudos da área de educação e sociologia política, principalmente remetendo-se à historicidade do tema no século XVI. Assim, para alguns especialistas, a origem do conceito de empowerment está relacionada ao movimento da Reforma Protestante, iniciada por Lutero quando questionou o poder tradicional da igreja na Alemanha por meio de 95 teses. A par disso, ele desafiou o clero aplicando um conjunto de críticas à igreja e à autoridade papal, motivo pelo qual veio modificar a partir daquele momento os rumos da religião e da autoridade política sobre muitas nações. Pode-se dizer que é o primeiro indicativo de uma perspectiva de elaboração conceitual do empowerment pela literatura e, mais tarde, absorvido pela corrente do liberalismo político (HEWITT, 2007; BAQUERO, 2012).

Assim, o conceito de empoderamento ocupou um espaço importante nas ciências

\footnotetext{
* Universidade Tecnológica Federal do Paraná (UTFPR), Pato Branco, Paraná, Brasil.
} 
sociais como consequência de estudos nas áreas de educação e política social no século passado. No tocante à primeira, existem estudos realizados pelo educador brasileiro Paulo Freire e o pedagogo norte-americano Ira Shor, durante os anos 1970, sobre o conceito de empowerment de classe em contraposição à corrente liberal vigente que priorizava o empoderamento individual, - o self made man (o homem que se faz pelo seu próprio esforço) - organizacional e psicológico preponderante nas ciências sociais aplicadas como na administração, economia, saúde pública e psicologia social norte americana. No que diz respeito à segunda questão, em meados dos anos 1980 surgiu a discussão sobre capital social, relacionado à participação política, cidadania e democracia, realizado sobretudo na área da ciência política por Coleman (1988) e Putnam (1997) e que tem servido de desdobramento para estudos sobre empowerment.

A partir dos anos 1990, os movimentos sociais passaram a buscar o empoderamento de pessoas e de grupos sociais que vivem em condições de risco e de extrema desigualdade social e política. As formas ultrapassadas de participação social e política passavam por mudanças e ressignificações em quase todos os países do Eixo Norte/Sul. Por conseguinte, não havia mais espaço para políticas tradicionais e verticalizadas, pois os contextos sociais e políticos não admitiam mais ações não-dialógicas e diretivas.

A propósito, durante aquele período, houve um impulso na disseminação de Ongs, fundações, sindicatos, associações e outras entidades de participação política em todo mundo. A condição para o sucesso de políticas, programas, projetos de um amplo leque de organizações, representantes de diferentes perspectivas políticas, de diferentes tamanhos, capacidade de influência e natureza tem a ver com o envolvimento social e político da sociedade e da comunidade nos destinos de suas histórias de vida (GOHN, 2004; ANTUNES, 2002; IORIO, 2002; ROMANO, 2002).

Assim, contextualiza-se o conceito de empowerment mostrando a complexidade e a multiplicidade de sentidos associado à categoria empoderamento, sempre que traduzido para outros idiomas, no decorrer do tempo, sobretudo quando utilizado nos diversos movimentos sociais e políticos desde os anos 1970 até a atualidade.
Assim, este artigo buscou a) examinar as implicações inerentes ao processo de empoderamento das lideranças Kaingang em contato com o Estado e a sociedade envolvente; b) analisar os processos políticos internos e externos exigidos no tocante a uma liderança local, regional e nacional; c) identificar as principais ferramentas acessadas pelas lideranças.

\section{Aspectos metodológicos}

No tocante à questão do referencial teórico para orientar o caminho da pesquisa e dos objetivos propostos, optou-se pelo encaminhamento da pesquisa por meio de uma abordagem do estudo do empoderamento bastante utilizado para examinar questões atinentes aos movimentos sociais, sobretudo aos grupos sociais e étnicos desprovidos e excluídos dos processos sociopolíticos e econômicos em vários continentes.

O estudo é de corte qualitativo e sustenta-se na teoria do empoderamento considerando a liderança indígena como categoria analítica. Com relação ao universo da pesquisa, Minayo (1999) afirma que uma boa amostragem é aquela que possibilita abranger a totalidade do problema investigado em suas múltiplas dimensões. Portanto, nesta investigação, procurou-se abranger a maior quantidade possível de lideranças e que a amostra fosse suficiente no sentido de constituir um universo qualitativo e heterogêneo de atores sociais.

A pesquisa foi realizada com um universo de 15 lideranças com perfis e estilos (liderança local, regional e nacional) de participação política bem diversificados no que tange ao campo de atuação política dentro do Estado nacional. Neste artigo, optou-se por nove depoimentos de lideranças indígenas que participaram da pesquisa sobre poder e empoderamento étnico. Assim, todos os entrevistados no momento da investigação assumiam alguma atividade política e/ou função social estratégica na comunidade e/ ou no âmbito do Estado nacional.

Além disso, a observação participante e a entrevista semiestruturada foram uma das técnicas de coleta de dados aplicados com os atores sociais envolvidos no movimento indígena no sul do Brasil. Além do mais, utilizou-se de outros instrumentos consagrados como: anotações de campo e depoimentos 
de lideranças políticas Kaingang na Terra Indígena Mangueirinha, sudoeste do Paraná.

\section{Contexto histórico do povo Kaingang}

A presença das populações indígenas no território paranaense, conforme estudos arqueológicos e antropológicos, é de cerca de 3 mil anos. Muitas análises apontam para a hipótese de deslocamento de habitantes de outras áreas no sentido da região sul do Brasil por algum motivo ainda desconhecido, embora um estudo de relevo geográfico mostre que se dirigiram a uma região de planalto semelhante ao seu habitat originário. Assim, o certo é que as pesquisas arqueológicas indicam que os Jê Meridionais (Kaingang e Xokleng) deslocaram-se do Brasil Central (nascentes do Rio São Francisco e Araguaia) em direção à região Centro-Sul estabelecendose nas regiões hoje conhecidas como estados do Paraná, Santa Catarina, Rio Grande do Sul e São Paulo, além da província de Missiones, na Argentina, aproximadamente por volta de 3 mil anos. Desse modo, não se tem ideia de quando teriam chegado à região que atualmente ocupam no sul do Brasil. Além disso, conforme Urban: "Tampouco se sabe por que migraram, embora um estudo do relevo geográfico mostre que se dirigiram a uma região de planalto semelhante ao habitat original" (URBAN, 1992, p. 90). Esse estudo vem reforçar a tese de que, na região do Planalto Meridional, habitavam povos originários conhecidos hoje como Guarani, Xetá, além de Kaingang e Xokleng (URBAN, 1992; NOELLI, 2000; TOMMASINO, 2000, VEIGA, 2006).

A grafia do termo Kaingang pode ser encontrada de diferentes maneiras ao longo da história de contato com o homem branco e as instituições sociais não-indígenas. Assim, como se pode notar, o termo aparece escrito em documentos jurídicos e históricos nas seguintes grafias: Caingang, Kaingangue, Kaingáng, Kaingang. Até nos apontamentos do reverendo Chagas Lima (1842), há nomenclatura referente aos índios Camé, Votoron, Dorin e Cayere que habitavam a região dos Campos de Guarapuava.

Como tal, a organização social e política Kaingang, historicamente, é baseada no sistema de metades exogâmicas, isto é, pela complementaridade entre os indivíduos que trazem a marca cultural conferida de Kamẽ e Kaĩru. Praticamente toda a cosmologia dos Kaingang perpassa pelas assimetrias entre o universo do mito de origem dos heróis ${ }^{1}$ e pelo faccionalismo. Ou seja, sistema dualista que se opõe e se engloba numa relação dialética de tensão e coesão social. Para falar desse contexto faccional e simbólico, Neoli Kafy, exvereador, líder indígena e residente da TI Rio das Cobras, município de Nova Laranjeiras, Sudoeste do Paraná, comentou: " [...] no meio Kaingang, nós temos as facções, né, quando entramos em atrito, o pau pega mesmo entre nós. A rivalidade é grande entre as marcas culturais, as pinturas de cada metade". Em suma, a organização sociocultural e política Kaingang opera pela dualidade clânica, o que orienta e fortalece o modus vivendi e o modus operandi da etnia.

\section{Empoderamento: algumas definições}

O debate sobre empoderamento tem gerado muitas interpretações e definições a respeito da terminologia, contudo a vasta polissemia conceitual não alterou a sua essência, que é a questão do poder (democracia, fortalecimento, autonomia) e de suas teias de relações dentro da sociedade e das instituições sociopolíticas. É possível que o termo empoderamento tenha incorporado e ganhado novos contornos com a sua utilização por outras áreas, a saber, no espaço do movimento indígena e das lideranças étnicas em vários continentes. A palavra é usada em contextos diferentes ${ }^{2}$ e por diversas organizações sociais e políticas alternativas bastante distintas,

\footnotetext{
${ }^{1}$ Segundo Curt Nimuendajú: "A tradição dos Kaingang conta que os primeiros desta nação saíram do chão [...] Saíram em dois grupos, chefiados por dois irmãos por nome Kañerú e Kamé, sendo que aquele saiu primeiro. Cada um já trouxe um número de gente de ambos os sexos. Dizem que Kañerú e sua gente toda eram de corpo fino, peludo, pés pequenos, ligeiros tanto nos seus movimentos como nas suas resoluções, cheios de iniciativa, mas de pouca persistência. Kamé e os seus companheiros, ao contrário, eram de corpo grosso, pés grandes, e vagarosos nos seus movimentos" (NIMUENDAJÚ, 1993, p. 9).

${ }^{2}$ A discussão em torno do verbete original empowerment na língua anglo-saxônica, e, sua correspondência empoderamento na língua portuguesa e empoderamiento no idioma espanhol, mostra a polissemia do vocábulo quando traduzido e usado em diferentes contextos sociopolíticos.
} 
basta apenas explorar o conceito na $W_{e b}^{3}$ para ver quantidade de experiências existentes.

A facilidade com que os movimentos sociais e as instituições políticas utilizam o conceito no seu cotidiano permitiu o emprego de tantas outras tentativas de definições. De um lado, o empoderamento aparece, na literatura progressista, como ações efetivas de melhoria da qualidade de vida, da autonomia, da participação política e do aumento da visão crítica da realidade social por parte dos grupos e dos atores sociais; de outro lado, observa-se a perspectiva conservadora centrada nas práticas de uma cidadania assistida e paternalistística apoiada em modelos estabelecidos e manipulatórios. A operacionalização é complexa e requer o compromisso social e consciente de quem estimula e implementa a emancipação política do sujeito no sentido freireano.

Por isso, no que concerne às organizações da sociedade civil e seu papel no empoderamento, há uma tensão entre os defensores de que elas se concentrem na prestação de serviços e os que preconizam a mobilização social. Autores críticos como Zimmerman (1988), Antunes (2002), Sen (1997), Romano (2002), Iorio (2002), Gohn (2004), Rowlands (2005), Horochovski (2007) compreendem que as ações mais exitosas são aquelas que rompem com assistência social (cidadania concedida ou manipulada), paternalismo, apatia e alienação dos atores envolvidos. Segundo esse entendimento, a autonomia e a postura crítica e criativa vindo de baixo para cima são ingredientes fundamentais para a mobilização social e a transformação da ordem existente. Como bem diz Freire (1986), ninguém empodera alguém, as pessoas empoderam-se entre si, mediadas pelo mundo de situações vivenciados. Assim, o trabalho em tela está embebido pela teoria social que coloca os sujeitos como atores ativos dos processos de mudanças.

Para Sen (1997), o empoderamento é, em primeiro lugar, uma abordagem sobre o poder, principalmente alterando as relações de poder em favor daqueles que anteriormente exerceram pouco poder sobre suas próprias vidas. Nesse sentido, a autora afirma: " [...] o empoderamento não é algo que pode ser

\footnotetext{
${ }^{3}$ World Wide Web que significa teia ou rede mundial.
}

feito a alguém por outra pessoa. Mudanças na consciência e auto-percepção são próprias, e quando elas ocorrem, podem ser explosiva e criativa" (SEN, 1997, p. 3).

No que tange à questão de que o empoderamento jamais poderá ser uma dádiva, uma concessão, ele deve ser um elemento poderoso de mudança nas pessoas. Nesse sentido, a autora ainda acrescenta de forma categórica:

Agentes de mudanças externas podem ser catalisadores essenciais, mas a dinâmica do processo de empoderamento é definida pela extensão e a rapidez com que as pessoas mudam a si mesma. Isso significa que, se os governos que capacitam as pessoas, elas se fortalecem. Isso significa que os governos não empoderam as pessoas; as pessoas empoderam-se. Assim, o que políticas governamentais e ações podem fazer é criar um ambiente favorável ou agir como uma barreira ao processo de empoderamento. (SEN, 1997, p. 3).

Entretanto existe uma diferença sutil quando comparadas as definições de empoderamento progressistas e conservadoras, surgindo em meio à visão tradicional a perspectiva fundada em valores neoliberais que afirmam:

[...] o empoderamento significa o fortalecimento da esfera privada, deixando-se às associações e comunidades a resolução de seus problemas. Combate-se, desse modo, políticas e programas estatais de assistência e bem-estar social. Sob o argumento de fortalecer as comunidades, o empoderamento assoma como justificativa para redução da despesa pública, dos impostos e da regulação estatal sobre as relações econômicas. (HOROCHOVSKI, 2007, p. 492).

A par disso, Villacorta e Rodríguez (2002) afirmam que o empoderamento é uma perspectiva que coloca as pessoas excluídas dos processos prevalecentes de desenvolvimento e do poder (sua distribuição e exercício) no centro do processo de desenvolvimento. Situar as pessoas e os grupos sociais que vivem na pobreza e/ou são excluídos do sistema dominante significa colocar as instituições econômicas (mercados) e as políticas (Estado) a serviço desses grupos, e não o contrário.

Para Villacorta e Rodríguez (2002, p. 47), o empoderamento é um processo de construção e/ou ampliação das capacidades 
que têm as pessoas e grupos pobres excluídos para: a) "Assumir o controle de seus próprios assuntos; b) produzir, criar, gerar novas alternativas; c) mobilizar suas energias para o respeito a seus direitos; d) mudar as relações de poder; e) poder discernir como escolher; $\mathrm{f}$ ) levar a cabo suas próprias opções."

De acordo com Iorio (2002), o empoderamento é uma perspectiva que põe as pessoas no centro do processo de desenvolvimento social e político. Não pode haver política de empoderamento se não houver o encorajamento das pessoas. Para ela, inserir as pessoas e os grupos vivendo na pobreza e/ou excluídos no interior do processo de desenvolvimento significa pôr as instituições econômicas (mercados) e políticas a serviço desses grupos. Hoje, é possível ver os grupos excluídos nos países pobres lutarem por políticas afirmativas no que concerne aos direitos sociais, culturais e políticos. Os movimentos sociais estão cada vez mais heterogêneos e pragmáticos em relação à agenda de reivindicações. A participação dos cidadãos no mundo da subpolítica é importante dentro do Estado-nação, no sentido de fortalecer a democracia e a participação ativas dos sujeitos.

Zimmerman (1988) e Rappaport (1995) afirmam que o empoderamento é uma construção que liga os pontos fortes das organizações e também as competências individuais, ajudando a fortalecer sistemas e comportamentos de pró-atividade quanto às questões de política social e de mudança social. Acredita-se ser um processo pelo qual os indivíduos ganham domínio e/ou controle sobre suas próprias vidas e participação democrática na vida da sua comunidade.

Horochovski (2007) lembra que a definição de empoderamento é próxima à noção de autonomia, pois refere-se à capacidade de indivíduos e grupos decidirem sobre as questões que lhes dizem respeito, escolher, enfim, entre cursos de ação alternativos em as múltiplas esferas política, econômica, cultural, psicológica, entre outras. De acordo com ele, é preciso compreender que, numa perspectiva emancipatória: "[...] empoderar é o processo pelo qual indivíduos, organizações e comunidades angariam recursos que lhes permitam ter voz, visibilidade, influência e capacidade de ação e decisão" (HOROCHOVSKI, 2007, p. 486). Desse modo, Antunes (2002), ao analisar a questão, acrescenta que o empoderamento é todo o acréscimo de poder que, induzido ou conquistado, permite aos indivíduos ou unidades familiares aumentarem a eficácia do seu exercício de cidadania.

Assim, a metodologia é gradual e complexa, de modo que não pode ser realizada jamais à revelia dos sujeitos políticos e dos grupos envolvidos. O processo de construção metodológico deve atingir o nível de complexidade das ações sociais para verdadeiramente compreender os fenômenos não revelados nem explicitados. Logo, o empoderamento deve implicar desfazer as construções sociais negativas, de forma que as pessoas atingidas cheguem a ver-se como possuidoras de capacidade e direito de atuar e ter influência. Rowlands (2005) afirma que, na concepção ampliada do empoderamento, cabe observar três dimensões importantes: a) Pessoal: aqui o empoderamento supõe o desenvolvimento do sentido do eu, da confiança e da capacidade individual, e desfazer os efeitos da opressão interiorizada. b) Relações próximas: aqui o empoderamento refere-se ao desenvolvimento da capacidade de negociar e de influir na natureza da relação e das decisões que se tomam dentro dela. c) Coletiva: quando os indivíduos trabalham conjuntamente para obter um impacto mais amplo do que poderia ter alcançado cada um deles em separado. Isso inclui a participação nas estruturas políticas; deveria abarcar também a ação coletiva baseada na cooperação e na competência. A ação coletiva pode estar centrada tanto em nível local, por exemplo, no âmbito do povo e do bairro como em nível institucional, seja redes nacionais e nas Nações Unidas.

O empoderamento de pessoas e grupos jamais pode ser algo linear e vindo de cima e sem a participação política direta dos sujeitos envolvidos e dos atores mais interessados no assunto. Os agentes externos do desenvolvimento, de maneira geral, não empoderam nem procuram discutir as relações de poder inerentes à ligação e à associação entre os projetos implementados e às comunidades. É comum não querer discutir as relações de comando e obediência no momento de implementação da política pública; a maneira mais sutil é desviar os conflitos e as reflexões críticas que, muitas vezes, são consideradas como perda de tutela sobre os sujeitos por 
parte de quem está no comando das políticas públicas. Rowlands (2005) lembra que qualquer noção de empoderamento outorgada por um ou outro grupo oculta uma intenção de manter o controle, pois o poder não pode ser concedido, todavia eleva de dentro e do cerne dos grupos e dos atores sociais.

Dessa maneira, Batliwala enfatiza que:

El processo de empoderamiento es, entoces, una espiral que altera la consciencia, identifica áreas de cambio, permite crear estratégias, promueve el cambio canaliza las acciones y los resultados, que a la vez permiten alcanzar niveles mas altos de conciencia y estrategias mas acordes con las necesidades y mejor ajecutadas. Visto así, el empoderamiento en espiral afecta a todos los involucrados: el individuo, el agente activista, la colectividad y la comunidad. Por ende, el empoderamiento no puede ser un proceso vertical o unilateral. (BATLIWALA, 1997, p. 201).

No dizer sempre expressivo de Sen (1997), o empoderamento e a autonomia não é algo que pode ser feito a alguém por outra pessoa, já que mudanças na consciência e na autopercepção são importantes e, quando elas ocorrem, podem ser a mais explosiva criatividade de energia, permitindo transformações, a partir do qual muitas vezes não há como voltar atrás. E, sendo assim, o empoderamento não pode ser feito por agentes de mudança externos, visto que a dinâmica do processo é definida pela extensão e a rapidez com que as pessoas mudam a si mesmas. Dessa maneira, conforme ela: "[...] os governos não capacitam as pessoas, elas se fortalecem. Que o que políticas governamentais e ações podem fazer é criar um ambiente favorável ou agir como uma barreira ao processo de empoderamento" (SEN, 1997, p. 3).

\section{Empoderamento: a palavra com as ideranças indígenas}

A categoria empoderamento foi aplicada tanto nos diálogos com lideranças indígenas, na TI Mangueirinha, quanto nos encontros agendados com os dirigentes vinculados à Funai, ArpinSul e Conselho dos Caciques do Paraná. Em relação às entrevistas realizadas, todas as lideranças foram questionadas sobre como veem a questão do empoderamento étnico, assim como a percepção delas sobre o fenômeno liderança indígena na atualidade.
Assim, a discussão a respeito do assunto revela aspectos importantes da interação social dos indígenas na sociedade envolvente e com o Estado nacional. Conforme Azelene Kaingang, socióloga e funcionária pública da Funai, o empoderamento está associado ao conhecimento técnico-científico conquistado com o envolvimento dos povos indígenas com a sociedade externa. Afinal, ela convive, há muito tempo, com a sociedade não indígena e participa ativamente representando os povos originários nos organismos nacionais e internacionais, o que, em certa medida, proporcionou-lhe acessar mecanismos e ferramentas técnico-científicas importantíssimas para o empoderamento individual, político e étnico (coletivo). De acordo com Azelene, a sociologia a ajudou muito a compreender a sociedade não índia e a qualificar a sua intervenção política nas discussões referentes às atividades promovidas pelos organismos internacionais como Organizações das Nações Unidas (ONU) e Organização Internacional do Trabalho (OIT) sobre os direitos dos povos indígenas. O discurso afirmativo de Azelene faz pensar na perspectiva sociológica do empoderamento como um recurso importante que impulsione os sujeitos e/ou grupos sociais a buscar a liberdade de expressão, a autonomia e a emancipação social, sobretudo em conjunturas políticas desiguais de relações de poder (ANTUNES, 2002; IORIO, 2002; SEN, 1997).

Azelene Kaingang, quando interpelada sobre a temática e o considerar-se uma liderança empoderada e capacitada para dialogar como porta-voz dos povos indígenas, no campo de intermediação dos organismos nacionais e internacionais, ela refletiu e respondeu:

Eu sim! Eu sim! Eu me considero uma militante empoderada né, porque eu tive acesso a coisas, porque eu tive acesso a mecanismos e a ferramentas e ao conhecimento técnico-científico do homem branco. Eu acho, que é assim, hoje, ele é indispensável para o empoderamento de qualquer liderança e de qualquer pessoa. Assim, por que eu posso ser uma liderança, uma liderança de base lá dentro do território indígena, entendeu. Mas, se eu não tiver um conhecimento técnico-científico ou se alguém não me explicar o que que é isso, eu não tenho condições de discutir alguns direitos fundamentais do meu povo. Por exemplo, as políticas públicas, cheia de 
conceitos, cheia de armadilhas para se discutir, né. Então, é necessário isso, daí uma forma de eu me empoderar foi acessar uma universidade. Acessar o conhecimento do homem branco, que eu não gosto dessa palavra homem branco, mas da sociedade não-indígena. (Azelene, socióloga e servidora pública na Funai).

O trecho acima revela um pouco a história da líder indígena em contato com o mundo das instituições políticas e sociais da sociedade ocidental. Suas reflexões críticas sobre o processo de como as políticas públicas são pensadas, desenhadas e elaboradas em gabinetes governamentais e escritórios não governamentais, sempre a portas fechadas e à revelia dos interesses dos povos autóctones. Ela lembra que uma elite togada e urbana, constituída por juristas, procuradores, parlamentares, consultores técnicos, indigenistas e antropólogos, elaborava, no passado, as leis e as políticas públicas sem que os maiores interessados participassem dos rumos do debate. A partir dos anos 1990, o Brasil tornou-se signatário de várias declarações internacionais sobre os direitos humanos e os povos indígenas brasileiros. Como parte legítima do processo em questão, passaram a reivindicar o direito de participação ativamente no debate de políticas públicas que dizem respeito à vida das populações tradicionais no Estado Nacional.

Azelene assinala que os conceitos e as definições de políticas indigenistas são elaborados de maneira tão abstrata e tão carregados de valores que não é possível serem entendidos pelas populações autóctones se não forem explicados claramente os significados, as estratégias e os efeitos deles na vida das comunidades indígenas. Segundo ela, às vezes, a explicação para algumas comunidades tradicionais, que não falavam português, muitas vezes, sucedia apenas na língua materna, no caso, o Kaingang. A explanação de Azelene sobre o processo de interação e o ato de transmitir o conhecimento aos caciques, no próprio idioma deles, faz lembrar o conceito de tradução cultural de Michaela Wolf (2008), que significa não transmissão literal e arbitrária de terminologias socioculturais, mas translação, deslocamento e mobilidade do outro sujeito que resiste - no caso, o interessado no processo de apropriação do novo conhecimento, que, comprometido com a tradução cultural, mostrará o significado real para as pessoas interessadas. Nesse sentido, a tarefa do tradutor é se envolver, transpor e agir no processo de construção de novos conhecimentos.

O testemunho da militante indígena, a seguir, revela a conscientização étnica e a habilidade para navegar nas duas culturas (a indígena e a da sociedade envolvente), articulando e negociando as garantias dos direitos políticos dos povos originários:

Eu conheço minha cultura. Eu domino melhor do que ninguém minha cultura. $\mathrm{O}$ que eu quero é o seu conhecimento, é o seu saber como não indígena para eu poder me defender de você mesmo, entendeu. Então, o empoderamento, essa forma de ter o poder, e de ter o conhecimento, porque informação hoje é poder, né. Ela dá para você, aliás, abre para você acessos importantes, que vão afunilando-se. De certa forma, eles vão afunilando-se, que não são todas as pessoas que têm acessos. E você vai fazendo parte, e você vai cada vez mais nesse afunilamentos fazendo parte de um grupo seleto de pessoas na medida em que você vai aprendendo. Ou seja, na medida em que você vai conhecendo, se informando. E mais do que isso, quando nós indígenas acessamos esses espaços como as universidades, a gente está contribuindo numa outra questão, que é de fazer as sociedades não-indígenas nos entenderem e também nos respeitarem. Porque eu acho, que você só respeita aquilo que você conhece. Se você não conhecer, você não respeita. Então, na medida que você vai também fazendo parte desse afunilamento, você também vai qualificando as pessoas para que elas conversem com você e te entendam. E, só fazendo um parêntese, quando eu participei da discussão da Declaração da ONU sobre os Direitos dos Povos Indígenas e outros fóruns internacionais, como o fórum da Terceira Conferência Mundial contra o racismo que aconteceu em Durban, na África do Sul, eu lembro que, numa pré-conferência que aconteceu em Genebra, Suíça, a gente discutia essa questão da adoção do termo povos indígenas dentro da Declaração, e, muitos países, não concordavam com esse termo. Por que, quando você fala povo, você fala o povo do mundo, o povo das américas, de uma forma bem genérico. Quando você fala povos, quando você coloca o " $\mathrm{s}$ ", agrega o "s", a essa palavra. Logo, você reconhece que ele é diverso. E que não existe um único 
povo, mas que existem muitos povos. Além disso, que são diversos entre eles e das sociedades que o cercam. Então, muitos países não aceitavam colocar "s" na palavra povos, porque aí eles teriam que reconhecer essa diversidade e proteger essa diversidade e adotar políticas para tanto. Então, muitos países não queriam reconhecer. (Azelene, socióloga e servidora da Funai).

Aliando ao discurso anterior, Azelene continuou narrando a experiência pessoal e política como representante dos povos indígenas das três américas na ONU, como integrante da delegação oficial do Brasil para discutir a Declaração das Nações Unidas sobre os Direitos dos Povos Indígenas, em 2006. Ela participou de todas as edições anteriores do evento, porém, em 2011, foi impedida pelo governo federal, por meio de uma notificação da própria Funai, de representar o Brasil na conferência da ONU. O órgão indigenista alegou que a indígena nunca representou o Estado brasileiro e, sim, os povos indígenas, por isso haveria de dar oportunidade para um outro servidor não indígena.

Retomando as narrativas pessoais de Azelene, ela contou minuciosamente sobre a sua intervenção política feita no fórum da ONU, em 2007, quando usou de cinco minutos para defender os direitos dos povos indígenas. Assim, conforme ela:

Aí, eu me lembro que, nessa época, eu fiz parte da delegação brasileira oficial para discutir essa questão. Havia um grupo fechado de discussões, que um diplomata brasileiro me convidou para participar. Aí um diplomata francês falava assim, porque eu tenho que reconhecer eles como povos diferentes? Por que olha ela é igual a mim, ela não tem diferença de mim. Ela é igual a mim. Por que eu tenho que reconhecer a ela direitos diferentes, ou seja, direitos além daqueles que eu tenho como cidadão francês? Aí, o diplomata brasileiro perguntou se eu queria responder. Eu disse, eu quero responder. Aí ele falou, olha como você tem dificuldade com o inglês. Então, você pode falar em português e eu transmito por inglês para a tradução da ONU, das Nações Unidas, repassar para todos presentes. Eu falei tá bom! E quando ele acabou de falar. Eu fiz o sinal para acender a luz do microfone, aí eu comecei a falar em língua Kaingang, eram uns quatros minutos que podia falar. Eu falei uns três minutos em idioma Kaingang. Aí a tradução da ONU parou, porque não tem tradução para língua Kaingang. Todo mundo ficou me olhando assim, né. O diplomata brasileiro olhando também. Por que eu não falei que iria falar em língua Kaingang. Quando faltava um minuto mais ou menos, eu falei em português. Eu perguntei, se ele tinha entendido o que eu falei ao diplomata francês. O diplomata brasileiro perguntou para ele. Ele disse (diplomata francês) que é óbvio que não tinha entendido nada. Eu falei, sabe por que você não entendeu, porque só um povo no mundo fala essa língua, que é o meu povo. Por isso, você não entendeu. É por isso que sou diferente de você. Então, de como o empoderamento, de como acessar mecanismos e ferramentas e espaços eles servem de estratégias políticas para a gente. Para a gente poder dessa forma contribuir não só de políticas, mas de legislações, de normas, de declarações, de pactos internacionais dos direitos humanos né, do direito internacional, em favor de nossos povos e de nossas comunidades. Então, eu me sinto uma militante empoderada exatamente por isso, porque eu conseguiu acessar mecanismos, ferramentas, espaços, saberes, conhecimentos, informações, culturas que me permitiram colaborar e contribuir não só com o meu povo, mas com os povos indígenas do Brasil, das Américas e do mundo. No sentido de assegurar e de garantir direitos que hoje estão aí, sendo discutidos, adotados, seguidos, gerando jurisprudência em julgamentos internacionais. Então, é assim, por isso, que me sinto uma militante empoderada. (Azelene, socióloga e servidora pública na Funai).

À medida que uma liderança étnica usa o próprio conhecimento do inimigo - expressão cunhada por ela - como estratégia política para defender os direitos políticos, sociais e coletivos dentro do Estado-nação, duas questões vêm à baila: a primeira questão tem a ver com o fato de os povos indígenas acessarem constantemente os sistemas culturais e os mecanismos formais para conquistar direitos e políticas dentro da sociedade envolvente. $\mathrm{Ou}$ seja, utilizarem as próprias armas do opressor para se defenderem com mais sabedoria e igualdade. A segunda questão refere-se aos limites e possibilidades de uma atuação afirmativa do movimento indígena dentro do Estado racional-legal. Assim, até onde a autonomia e a liberdade dos povos originários são preservados - pela tradição dos grupos sem que se confundam com os conceitos de 
liberdade vigiada e autonomia relativa dos sujeitos dentro do Estado moderno.

No tocante à questão da afirmação política dos direitos originários, a Constituição da República Federativa do Brasil, promulgada em 5 de outubro de 1988, no Capítulo VIII, Dos Índios, é um exemplo desse protagonismo indígena durante as últimas décadas no Brasil. Não quer isso dizer que os direitos presentes nos livros e nos manuais jurídicos sejam efetivados na prática. É preciso constantemente lutar para afirmar e materializar o direito que está nos livros como realidade social dos povos indígenas e não indígenas desprotegidos. Para Ari Paliano, advogado e liderança Kaingang, é preciso que o índio aproprie-se fundamentalmente da "técnica-jurídica, para que ele vá prá frente e use a nosso favor do nosso povo e das comunidades", completou. $\mathrm{Na}$ mesma linha de entendimento, Rildo Mendes, coordenador técnico da ArpinSul e morador do Toldo Imbu, Santa Catarina, sustentou o argumento anterior: "se uma liderança tem o conhecimento técnico acima dos demais, ela consegue ter maior poder de decisão na esfera regional e local".

Uma reflexão que deve ser feita é sobre quando as lideranças aprendem a reivindicar e a negociar na arena de disputas no Estadonação. A ação delas pode interferir no desenho das políticas públicas específicas, além de rever a maneira como o sistema de poder lida com as questões que lhes dizem respeito cotidianamente. É importante salientar que, nesse processo político no campo da intermediação política, todos aprendem a jogar o jogo, inclusive as próprias lideranças indígenas. Normalmente, elas tornam-se mais conscientes da realidade e aparecem como sujeitos de direitos visíveis à sociedade envolvente. É óbvio que isso incomoda as instituições sociopolíticas que, dependendo da conjuntura, são obrigadas a revisar as práticas de intervenção social, ora para acatar as demandas coletivas dos movimentos sociais, ora recuar e reprimir as reivindicações coletivas.

O despertar para o empoderamento individual, político e coletivo foi narrado pelo cacique Valdir: "Então, eu não conhecia Funai, não conhecia o Estado, as autoridades, deputado, governador e nem prefeito daqui de Mangueirinha. Eu fui aprendendo, participando e me envolvendo com a sociedade local e as instituições de governo". De fato, as lideranças recebem geralmente as primeiras lições de governança, de formação política na base, para, em seguida, lançarem-se na luta em defesa da política indígena regional em que vão conhecer os meandros das instituições governamentais. Nesse momento de ativismo político, elas acabam circulando bastante por áreas e conhecendo a realidade socioeconômica e política de outras comunidades indígenas.

De acordo com o cacique Valdir, a aprendizagem com as instituições políticas o fortaleceu politicamente a ponto de ser sempre consultado por outras lideranças sobre diversos assuntos, inclusive, já prestou orientação política para o Conselho Estadual dos Caciques do Paraná e o Conselho Regional dos Caciques de Guarapuava, Paraná. Assim, as entidades referidas buscavam seu auxílio quando se tratava de decisões importantes sobre política indigenista regional. Iorio (2002, p. 29) esclarece que "[...] as pessoas empoderam-se a si mesmas". Em razão disso, Antunes (2002) explica que o empoderamento não é algo feito por alguém a outra pessoa. É uma conquista e ainda mais um estímulo individual e coletivo. $\mathrm{O}$ sentido verdadeiro é a transformação do poder de baixo para cima, isto é, a conscientização política como prática poderosa em face de todo e qualquer processo que seja neutro, despolitizado e não emancipatório dos sujeitos (FREIRE, 1986; SEN, 1997; IORIO, 2002; ROMANO, 2002).

Romancil Cretã, articulador político da ArpinSul, atestou o argumento do cacique Valdir a respeito do empoderamento e declarou-se decisivo quando se trata de articulação política dos povos indígenas no Sul do Brasil. Assim, questionado se ele se considerava uma liderança empoderada, afirmou:

[...] Eu acho que sim. Eu acho que eu tenho esse empoderamento. Eu percebo, às vezes, que a minha liderança assusta muito. Por que eu consigo com um simples telefonema, hoje, e com uma conversa com outras lideranças, a gente consegue fazer um movimento imediato. Então, eu acredito que eu tenha esse empoderamento. E o empoderamento não só pela questão de você fazer reivindicações, mas, o empoderamento de você adquirir o conhecimento também, conhecimentos políticos, saber avaliar a conjuntura política independente 
do governo que está no Estado ou Governo Federal. Você saber que nem um governo é igual a outro. O Governo do Paraná você tem que trabalhar de um jeito com ele, o de Santa Catarina, de outro e o do Rio Grande do Sul, de outro. Mas, você tem que tentar, ter estratégias de dialogar com cada um deles no dia-a-dia. Então, eu acredito que isso é o empoderamento de você entender e saber atuar na esfera das negociações. Não é só pelo poder de você chegar e vamos fazer um movimento agora. Não é só disso! O empoderamento, desde o entendimento político que você tem dos direitos. Você saber, quando você está na frente de um Deputado Federal, quando você está na frente de um Senador, de uma Governador, do Prefeito. Você saber a postura que você tem que ter perante ele. Quando é uma pessoa que você quer amedrontar ele, para ele ficar e se preparar que o próximo é ele dentro de uma reivindicação. Tem o jeito, eu consigo fazer essas falas. Essas estratégias. Eu consigo assustar as pessoas desse jeito. Para mim, o empoderamento é você ter o conhecimento do que você vai fazer naquele momento. E tem que ser iluminado também, porque se você não for iluminado. Então, eu acredito que seja isso o empoderamento. (Romancil Cretã, coordenador político da ArpinSul).

Em outras palavras, Romancil explica que é fundamental as lideranças desenvolverem uma visão crítica de mundo no campo da intermediação, isto é, atingirem uma conscientização política aliada à estratégia de ação no campo de disputas de poder.

Adir, coordenador técnico da Funai, refletindo sobre a questão do poder institucionalizado e as obrigações enquanto indígena no exercício da função, explicou que, para a função dele, é necessário conhecimento técnico-científico e está bem atualizado. Por isso, o líder precisa saber acolher todas as demandas comunitárias e negociá-las a ponto de transformá-las em ações efetivas de políticas públicas de assistência aos direitos dos povos indígenas. Assim, no tocante à questão do empoderamento, ele respondeu:

Não deixa de ter. O cargo que você ocupa, se você não tiver um pouco desse empoderamento, dessa capacidade de liderar, você também não permanece. Você tem um pouco de poder, você não pode esquecer que tem obrigações a cumprir com o governo. No meu caso, eu tenho obrigações a cumprir com o governo, com a instituição
(Funai), que são metas a serem desenvolvidas dentro das comunidades. São normas burocráticas que têm de ser seguidas. Não deixa de ter um pouco de poder, porque você, na hora que você escreve um projeto, detalha um projeto junto com a comunidade, está representando o que você aprendeu e mostrando para a comunidade na prática. A comunidade começa a ver com outros olhos. O projeto começa a ganhar corpo. Eles começam também a te respeitar como líder. Mas eu não me considero uma liderança comunitária. Eu me considero, tenho até uma certa liderança. Liderança que vem de mim. Mas não que eu seja uma liderança indígena. Eu sou mais um braço do Governo Federal a serviço das comunidades indígenas. Trabalhando pelo Governo nas comunidades indígenas. (Adir, coordenador técnico local da Funai).

Valfride, professor bilíngue, falou que se sente fortalecido e empoderado apenas para dar sugestões e orientar as lideranças na comunidade. Ele explicou que gostaria de exercitar mais o papel de intermediador político entre as duas culturas - a indígena e a do branco. Assim, sempre que as lideranças internas, ligadas ao cacique, pediam algum auxílio e/ou orientação, nunca hesitou, sempre aconselhava e participava das atividades políticas internas. Em suma, ele declarou que o objetivo é trazer para a comunidade os temas importantes que ocorrem externamente e traduzir internamente para seu povo. Dessa maneira, ele considera que:

O único poder que eu tenho como professor, é de orientar. Por exemplo, seria isso meu trabalho, e é isso que eu quero exercer. Ter o poder, assim, de orientar as pessoas do que acontece lá fora, na sociedade não-indígena. E que nós também estamos inseridos e que nós somos diferentes. Como eu sempre falo, a gente é assim um povo, ainda, que vive na coletividade. Se você cair fora dessa coletividade, as coisas perecem. Então, a nossa força, desde antes, é a coletividade, a comunidade. Porque você sozinho não consegue fazer nada! Pode notar até a questão, das manifestações contra isso e contra aquilo. Então, se você não só nas sociedades indígenas, mas também nas sociedades não indígenas acontece isso. É a força do grupo. Eu sempre converso com o pessoal aqui da Terra Indígena Mangueirinha, sozinho você não vai fazer nada. Então se você está engrupado, aí a coisa anda. (Valfride, professor bilíngue da Escola Estadual Indígena Jykre Tãg). 
Nota-se que, Ivan, advogado e militante político da Terra Indígena Apucaraninha, município de Tamarana, localizado no Norte do Paraná, afirmou conhecer a temática, porém, não se considera ainda empoderado, porque não vê efetivamente canais que facilitem a participação indígena na vida política dentro do Estado nacional. De acordo com Ivan "[...] o empoderamento só vai chegar quando ocuparmos cargos nos três poderes essenciais do País, por exemplo, no poder executivo, legislativo e judiciário, para termos o poder da caneta e usar a favor dos povos indígenas". De acordo com ele, é preciso que os povos indígenas assumam posições estratégicas no Estado-nação, sobretudo participando de decisões importantes a respeito das políticas públicas e direitos indígenas.

O pouco espaço reservado aos povos indígenas na sociedade vem motivando os representantes étnicos a buscar o aprimoramento educacional como recurso político e cultural poderoso para interagir com as instituições jurídico-políticos na América Latina. Assim, Ulloa (2004) cita o exemplo da Colômbia, onde os povos originários conquistaram avanços significativos depois que o Estado colombiano proporcionou um processo de descentralização administrativa e revisão constitucional, em 1991. Vale ressaltar, ainda, que o País ratificou a Convenção 169, da OIT, em 1989, reconhecendo os índios como cidadãos com plenos direitos de manter a sua identidade e seus territórios tradicionais. Convém notar, outrossim, que, além dessas conquistas anteriores, o movimento indígena colombiano conquistou uma jurisdição eleitoral especial que garante aos povos originários daquele país duas representações no Senado Federal colombiano.

\section{Considerações finais}

As exigências destacadas anteriormente demandam das lideranças habilidades para interagir e transitar construindo redes de relações sociais com a sociedade não indígena. Com efeito, a construção de alianças com outros movimentos sociais e políticos é uma estratégia de sobrevivência política para além dos aldeamentos. Portanto saber interagir no mundo dos brancos, sobretudo nas instituições sociais, poderá render experiências importantes para o bom exercício tanto dentro quanto fora da aldeia. Então, expressar-se bem no idioma português, no sentido de discutir com desenvoltura acerca das políticas indigenistas, é um diferencial importante no campo social e político.

Dado interessante que emergiu nas falas dos entrevistados é a tendência das novas gerações de Kaingang em alcançarem níveis de instrução elevados, sobretudo acadêmicos, como uma ferramenta fundamental para compreender e interpretar as políticas públicas, os códigos, as leis, as resoluções nacionais e internacionais da sociedade não indígena. $\mathrm{O}$ fato de os novos protagonistas buscarem conhecimento para compreender as políticas públicas tem a ver com a dificuldade das lideranças mais velhas ou tradicionais de lidarem com os conceitos abstratos existentes nas políticas indigenistas na atualidade.

Aliado à questão anterior, o estudo demonstrou que os Kaingang, além de exigirem de seus representantes determinadas condutas e distintivos inerentes a um líder étnico (confiança, respeito, tradição familiar, linhagem clânicas etc.), também vêm sinalizando para um tipo de ator político com alto grau de instrução. Ou seja, o entendimento é de que, no mundo atual, não se pode mais viver totalmente isolado, apenas do conhecimento tradicional e das leis internas do grupo. Muitos entrevistados relataram a necessidade de aprender - aprender para defender-se do inimigo. O confronto com este já não será mais por meio dos instrumentos de guerra do passado guerreiro como o arco e flecha, usando uma metáfora recorrente entre eles na TI Mangueirinha, mas, sobretudo por meio do 'papel e da tinta'. O fato é que a apropriação do conhecimento não indígena pelo índio é visto pelo Kaingang como um recurso político importante para negociar projetos comunitários, verbas públicas, cargos políticos e legislação indigenista.

Então, ainda em relação à questão dos atores sociais, a investigação revela que os perfis das lideranças são base-intermediárianacional, mas, não é uma regra geral para todos os povos. Eles podem mudar e tomar outros contornos conforme as especificidades e a conjuntura sociopolítica de cada grupo étnico. Apesar da complexidade dos fenômenos estudados, pode-se dizer que os Kaingang 
seguem essa lógica de representação política. Assim, a legitimidade de uma liderança está na sua capacidade de articular os trabalhos entre aldeia-cidade-aldeia sem perder o vínculo social e político com qualquer uma das esferas.

Ainda, observa-se que o papel político e cultural das diversas lideranças é muito importante para os Kaingang. Eles são representantes fundamentais das comunidades dentro do Estado-nação. No caso específico dos Kaingang, é mais significativo estar bem representado, sobretudo no sul do Brasil, onde as lideranças de base têm um papel muito importante dentro dos aldeamentos. Assim, a comunidade acaba sendo um grande laboratório de formação política de lideranças de base que vai lapidando para outros ambientes como o regional e o nacional.

\section{Referências}

ANTUNES, Marta. O caminho do empoderamento: articulando as noções de desenvolvimento, pobreza e empoderamento. In: ROMANO, Jorge; ANTUNES, Marta (Org.). Empoderamento e direitos de combate à pobreza. Rio de Janeiro: ActionAid Brasil, 2002. p. 91-116.

BAQUERO, Ruth Vivian Angelo. Empoderamento: instrumento de emancipação social? - uma discussão conceitual. Revista Debates, Porto Alegre, v. 6, n. 1, p. 173-187, 2012.

BATLIWALA, Srilatha. El significado del empoderamiento de las mujeres: nuevos conceptos desde la acción. In: LEÓN, Magdalena (Comp.). Poder y empoderamiento de las mujeres. Santa Fé Bogotá: Tercer Mundo Editores, 1997. p. 187-211.

CHAGAS LIMA, Francisco. Memória sobre o descobrimento e colonia de Guarapuava. Revista Trimensal de Historia e Geographia ou Jornal do Instituto Historico e Geographico Brasileiro, Rio de Janeiro, tomo IV, n. 13, p. 43-64, 1842.

COLEMAN, James S. Social capital in the creation of human capital. American Journal of Sociology, v. 94, p. 95-120, jul. 1988. Suplemento.

FREIRE, Paulo; SHOR, Ira. Medo e ousadia: o cotidiano do professor. Rio de janeiro: Paz e Terra, 1986.

GOHN, Maria da Glória. Empoderamento e participação da comunidade em políticas sociais. Saúde e Sociedade, São Paulo, v. 13, n. 2, p. 20-31, maio/ago. 2004. Disponível em: <http://www.scielo.br>. Acesso em: 10 jun. 2008.

HEWITT, Hugh. Blog: entenda a revolução que vai mudar o seu mundo. Rio de Janeiro: Thomas Nelson, 2007.

HOROCHOVSKI, Rodrigo R.; MEIRELLES, Giselle. Problematizando o conceito de empoderamento. In: SEMINÁRIO NACIONAL MOVIMENTOS SOCIAIS, PARTICIPAÇÃO E DEMOCRACIA, 2., 2007,
Florianópolis. Anais... Florianópolis: Núcleo de Pesquisa em Movimentos Sociais, UFSC, 2007, p. 485-506.

IORIO, Cecília. Algumas considerações sobre estratégias de empoderamento e de direitos. In: ROMANO, Jorge; ANTUNES, Marta (Org.). Empoderamento e direitos de combate à pobreza. Rio de Janeiro: ActionAid Brasil, 2002. p. 21-44.

MINAYO, Maria Cecília de Souza (Org.). Pesquisa social: teoria, método e criatividade. 12. ed. Petrópolis, RJ: Vozes, 1999

NIMUENDAJÚ, Curt. Notas sobre organização religiosa e social dos indios Kaingang. Campinas: Unicamp, 1993, p. 57-66.

NOELLI, Francisco Silva. Repensando os rótulos e a história dos Jê no Sul do Brasil a partir de uma interpretação interdisciplinar. In: MOTA, Lúcio Tadeu; NOELLI, Francisco Silva; TOMMASINO, Kimiye (Org.). Uri e Wãxi: estudos interdisciplinares dos Kaingang. Londrina: Editora UEL, 2000.

PUTNAM, Robert D. Comunidade e democracia: a experiência da Itália moderna. Rio de Janeiro: Fundação Getúlio Vargas, 1997.

RAPPAPORT, Julian. Empowerment meets narrative: listening to stories and creating settings. American Journal of Community Psychology, v. 23, n. 5, 1995.

ROMANO, Jorge O. Empoderamento: recuperando a questão do poder no combate à pobreza. In: ROMANO, Jorge O; ANTUNES, Marta (Org.). Empoderamento e direitos de combate à pobreza. Rio de Janeiro: ActionAid Brasil, 2002. p. 9-44.

ROWLANDS, Jô. El empoderamiento a examen. 2005. Disponível em: <http:/ / www.governabilidad.cl/modules. php? name $=$ News\&file $=$ article\&sid $=809>$. Acesso em: 11 abr. 2009.

SEN, Gita. Empowerment as an approach to poverty. Working Paper Series, n. 97.07, dez. 1997.

TOMMASINO, Kimiye. Território e territorialidade Kaingang. Resistência cultural e historicidade de um grupo Jê. In: MOTA, Lúcio Tadeu; NOELLI, Francisco Silva; TOMMASINO, Kimiye (Org.). Uri e Wãxi: estudos interdisciplinares dos Kaingang. Londrina: Editora UEL, 2000.

ULLOA, Astrid. La construcción del nativo ecológico: complejidades, paradojas y dilemas de la relación entre los movimientos indígenas y el ambientalismo en Colombia. Bogotá, Colombia: Instituto Colombiano de Antropología e Historia, 2004.

URBAN, Greg. A história da cultura brasileira segundo as línguas nativas. In: CUNHA, Manuela Carneiro (Org.). História dos índios no Brasil. São Paulo: Companhia das Letras, 1992. p. 87-102.

VEIGA, Juracilda. Aspectos fundamentais da cultura Kaingang. Campinas, SP: Curt Nimuendajú, 2006.

VILLACORTA, Alberto E.; RODRÍGUEZ, Marcos. Metodologias e ferramentas para implementar estratégias de empoderamento. In: ROMANO, Jorge; ANTUNES, Marta (Org.). Empoderamento e direitos de combate à pobreza. Rio de Janeiro: ActionAid Brasil, 2002. p. 45-66.

ZIMMERMAN, Marc A.; RAPPAPORT, Julian. Citizen participation, perceived control, and psychological 
empowerment. American Journal of Community Psychology, v. 16, n. 5, p. 725- 750, 1988.

WOLF, Michaela. Translation - Transculturation. Measuring the perspectives of transcultural political action.
Translated by Kate Sturge. Transversal: eipcp multilingual webjournal, Viena, Austria, abr. 2008. Disponível em: <http://eipcp.net/transversal/0608/wolf/en>. Acesso em: 22 maio 2011. 